\title{
THE INFLUENCE OF SMALL DOSES OF ALCOHOL ON THE CAPACITY FOR MUSCULAR WORK.
}

\author{
By W. H. R. RIVERS AND H. N. WEBBER.
}

\begin{abstract}
Experimental methods. Use of control substances. Doses varying from 5 to 20 c.c. of pure alcohol without effect on the capacity for muscular work when the factors of interest, sensory stimulation and suggestion are excluded.
\end{abstract}

Ir may seem that some apology is needed for publishing an account of the influence of a drug on the capacity for muscular work in a journal of psychology. The chief interest of our work, however, lies in the demonstration we give of the part played by purely psychical factors in the mode of measuring muscular work which is usually employed in the investigation of the action of drugs, and the chief importance of the work lies in its contribution to the study of the methods by which the influence of these psychical factors may be excluded.

Most of those who have tested the action of alcohol on the capacity for muscular work in man have obtained very definite and positive results with small doses, and we hope to show that these results have almost certainly been due to the neglect of certain factors which have influenced their work. We do not propose to give a full account of this previous work with small doses of alcohol ${ }^{1}$ but are content to say here that some investigators (Lombard ${ }^{2}$, Rossi $^{3}$, Frey $^{4}$, and in some persons, Joteyko ${ }^{5}$ ) have found the amount of work decidedly increased after

1 A full account of the history of the subject has been given by one of us in the Croonian Lectures given at the Royal College of Physicians in 1906 (to be published shortly).

2 Journ. Physiol. 1892, Vol. xrrr. p. 49.

3 Rivista sper. di Freniatria, 1894, Vol. xx. p. 148.

+ Mitth. aus Kliniken u. med. Instituten d. Schweiz, 1896, Reihe Iv. Hit. I. and Alkohol 11. Muskelermildung, Leipzig $u$. Wien, 1903.

5 Travaux du Laboratoire de Physiologie (Instituts Solvay), 1904, T. vI. p. 361. 
doses varying from 5 to 20 c.c. of absolute alcohol; others (Destrée ${ }^{1}$, and in some persons, Joteyko) have found a decided decrease with these doses, while others again (Scheffer ${ }^{2}$ and Féré $^{3}$ ) have found an initial increase followed by a fall below the normal. Others again, such as Schumburg ${ }^{4}$ and Schnyder ${ }^{5}$, obtained positive results, but found that these varied in nature according to certain conditions of the experiment.

All these investigators have compared the work done on days when alcohol was taken with that of other days when nothing was taken, and none of them have used on the normal days a control substance which would have prevented the subjects under experiment from knowing whether any given day was one on which the action of the alcobol was being tested or was one of the normal days.

That psychological factors play a part in the measurement of muscular work has been acknowledged by most investigators, but they have usually considered those coming under the heading of suggestion only and even the knowledge of this influence has not led them to adopt any means for its elimination. Féré ${ }^{6}$ has drawn attention to the great influence of sensory stimulation on the capacity for muscular work, but even here it does not seem to have occurred to him to employ any adequate controls in his extensive researches on the action of drugs. No previous workers, so far as we know, have paid any attention to what we believe to be a far more potent source of error than either suggestion or sensory stimulation, viz., the interest and excitement produced by the act of taking the alcohol, and much of the work on the action of alcohol has been done by giving this substance, not in the pure state, but in one of the forms in which it is taken in everyday life-a procedure calculated to enhance the part taken by interest.

The special feature of our work is that it has been done with the aid of control substances so that we have disguised from ourselves whether, on any given occasion, we were taking alcohol or not, and have thus eliminated all possible effects of suggestion, sensory stimulation and interest.

Owing to the special flavour and pungency of alcohol it was not easy to discover adequate means of control. In this we owe very much

\footnotetext{
1 Journ. méd. de Bruxelles, 1897, nos. 44 and 47.

2 Arch. f. exp. Pathol. u. Pharmakologie, 1900, Bd. xuIv. S. 24.

3 Travail et Plaisir, Paris, 1906, p. 301.

4 Arch.f. Anat. u. Physiol., Physiol. Abth. Suppt. Bd. 1899.

5 Arch. f. d. ges. Physiologie, 1903, Bd. xcilr. S. 45.

6 op. cit.
} 
to the kind help of Dr W. E. Dixon who in most cases prepared our mixtures for us, lettering them only, so that it was not till after an experiment was concluded that we learnt which of the bottles we had been given contained alcohol. The most successful control mixture was found to be one containing capsicum, cardamoms, chloroform and peppermint, these substances being also put into the mixtures containing the alcohol. Further in order to assist the control, we always took in any experiment two different doses of alcohol. If there were any effect, it should vary with the dose, while the fact that two different strengths of alcohol were being taken, helped to complete the disguise.

In most of our experiments the disguise was completely successful. Occasionally we might suspect the presence of alcohol, either from taste or from sensations localised in the epigastrium, but these were in general vague and often incorrect; only in one experiment did the control fail entirely. With the doses with which we are concerned in this article we did not become aware that we had taken alcohol by means of any after-effects as has often been the case with larger doses. Any differences in taste were so slight that we certainly excluded the influence of sensory stimulation, and even when the presence of alcohol was suspected there was so much uncertainty that the influence of suggestion may also be confidently excluded. There remains the effect of interest. In one case there is little doubt that the interest aroused by (correct) suspicions as to the nature of the dose increased the amount of work, but in all other cases the disguise was either so complete or the suspicions awakened were so indefinite as to make it very unlikely that there were differences in interest sufficient to affect the amount of work.

We used the modification of Mosso's ergograph devised by Kraepelin, a very perfect instrument, in which various sources of error which vitiate much work on the action of alcohol are entirely avoided, the most essential features being the absolute guarantee that the movements throughout are limited to one joint and that the point of application to the finger of the cord carrying the weight is always at the same distance from this joint.

Another feature of our method, which has been used by Frey but not by other workers on alcohol, was to test the action of the drug on sets of ergograms separated by intervals of rest. In our earlier work we recorded three sets, each of six ergograms, at halfhour intervals, while in our later experiments a larger number of 
sets were recorded with longer periods of rest between the later sets. In all cases the interval between the ergograms of a set was two minutes and the rhythm of each ergogram was one of two seconds, the finger being flexed with one beat and relaxed with the next beat of a metronome beating seconds. In some experiments the dose; whether of alcohol or 'control,' was taken shortly before the beginning of the second set of ergograms; in other experiments it was taken during the interval between the first and second ergograms of the first set. Thus the first ergogram of every day was taken under similar conditions, and in order to show the action of the drug we always express the work of every ergogram in percentages of the work of the first ergogram. The weight used in all the experiments recorded in this paper was $4.5 \mathrm{~kg}$.

Each experiment lasted for a number of days on some of which one dose of alcohol was taken, on others a different dose and on the rest, either the control mixture or nothing at all. Every effort was made to keep the different days as alike as possible; the work was begun at the same time every day, at the same interval after a meal of the same kind and amount. This latter point is very important, for Schnyder has found that there is a difference in the action of alcohol according as it is taken during or soon after a meal or at a considerable interval, and in our experiments the work was always begun half an hour after a light meal. The other conditions of life on the different days of the experiment were kept as equable as possible; the same amount of other work was done, the same amount of exercise was taken at the same times, and such disturbing factors as social engagements were eschewed. As far as possible the same amount of sleep was taken each night.

Further, during the whole course of the experiments lasting over many months all articles of diet containing caffeine or alcohol were avoided, and by one of us (R.) had been avoided for more than a year before the experiments began. The other of us (W.) had always been a total abstainer from alcohol.

The experiments were preceded by some initial training which is very necessary in the use of the ergograph, but we did not wait to begin our experiments till we were completely trained, so that our work has been done in different conditions of training.

In the case of one of us (R.) the work with the ergograph was much hampered by muscular pain, and partly for this reason, partly because his time could not be wholly given to the work, the experiments of the other (W.) are more extensive and more satisfactory and will be considered first. 
The experiments of the subject $W$.

Experiment i. In this experiment three sets of ergograms were recorded with half-hour intervals between the sets. During the intervals the subject adjusted the apparatus and took readings while the other of us was carrying out an experiment, so that he was occupied in mental and muscular work of a gentle kind. The doses of alcohol were 5 and 10 c.c., and both these and the control mixture were taken in a tumbler of water ten minutes before the beginning of the second set. The experiment was conducted in March, 1906, on the mornings of twelve days half an hour after a light breakfast. On six days the right hand was used and on the other six the left hand. There was no difference between the results with the two hauds, and the figures are grouped together in the following table and curves.

TABLE I. Experiment W. i. Work. Average day. Both hands. Weight $4.5 \mathrm{~kg}$. Dose 10 minutes before second set.

\begin{tabular}{|c|c|c|c|c|c|c|c|c|c|}
\hline & \multicolumn{3}{|c|}{ First set } & \multicolumn{3}{|c|}{ Second set } & \multicolumn{3}{|c|}{ Third set } \\
\hline & m Control & $\begin{array}{l}5 \text { c.c. } \\
\text { Alcohol }\end{array}$ & $\begin{array}{l}\text { 10 c.c. } \\
\text { Alcohol }\end{array}$ & & $\begin{array}{l}5 \text { c.c. } \\
\text { Alcohol }\end{array}$ & $\begin{array}{l}10 \text { c.c. } \\
\text { Alcohol }\end{array}$ & & $\begin{array}{l}5 \text { c.c. } \\
\text { Alcohol }\end{array}$ & $\begin{array}{l}10 \mathrm{ccc} \text {. } \\
\text { Alcohol }\end{array}$ \\
\hline 1 & $5 \cdot 1(100)$ & $6 \cdot 2(100)$ & $6 \cdot 2(100)$ & $3 \cdot 4(66)$ & $3 \cdot 9(64)$ & $4.0(66)$ & $3 \cdot 3(63)$ & $2 \cdot 7(43)$ & 3.816 \\
\hline 2 & $1.9(35)$ & $2 \cdot 0(34)$ & $2 \cdot 4(40)$ & $1 \cdot 2(22)$ & $1 \cdot 4(24)$ & $1 \cdot 5(24)$ & $1.2(21)$ & $1 \cdot 3(20)$ & 1.6( \\
\hline 3 & $1.5(27)$ & $1.5(26)$ & $1 \cdot 6(26)$ & $0.9(15)$ & $0.9(15)$ & $1 \cdot 1(18)$ & $1.0(18)$ & $1.0(14)$ & $1 \cdot 4(22)$ \\
\hline 4 & $1 \cdot 3(23)$ & $1 \cdot 6(2 \bar{o})$ & $1.5(25)$ & $0.8(13)$ & 0.7 (13) & $1 \cdot 3(21)$ & $0.9(16)$ & $0.8(12)$ & $1.0(16$ \\
\hline 5 & $1 \cdot 2(21)$ & $1.2(20)$ & $1.4(22)$ & $0.9(16)$ & $0.5(8)$ & $0.9(14)$ & $0.8(13)$ & $0.7(10)$ & $1 \cdot 1(18$ \\
\hline 6 & $1 \cdot 2(23)$ & $1.0(16)$ & $1 \cdot 3(20)$ & $0.8(14)$ & $0.5(9)$ & $0.8(13)$ & $0.9(14)$ & $0.7(11)$ & $0.9(1$ \\
\hline Total & $12 \cdot 2(100)$ & $13 \cdot 5(100)$ & $14 \cdot 4(100)$ & $8.0(62)$ & $7 \cdot 9(59)$ & $9 \cdot 6(67)$ & $8 \cdot 1(62)$ & $7 \cdot 2(49)$ & $9 \cdot 8(6$ \\
\hline
\end{tabular}

In Table I. we give in kilogrammetres the work of the average ergograms, each figure showing the average of the ergograms of four days. As the dose, whether of alcohol or control, was not taken till ten minutes before the beginning of the second set, the ergograms of the first set were taken under the same conditions on the three groups of days and they should, therefore, correspond. It will be seen that in absolute amount the figures on the control days are rather smaller than on the two alcohol days, owing to some difference of disposition on the different days. The course of the ergograms of each set however; as shown by the figures in brackets, which give the amounts as percentages of the first ergogram, run very closely together. This is also shown in the lowermost curves of Fig. 1 where the course of the ergograms is shown graphically, and the correspondence of the three curves for the work of the first set is 
as close as could be desired. The total amounts for the work of the second set, given in the bottom line of the table, show that rather

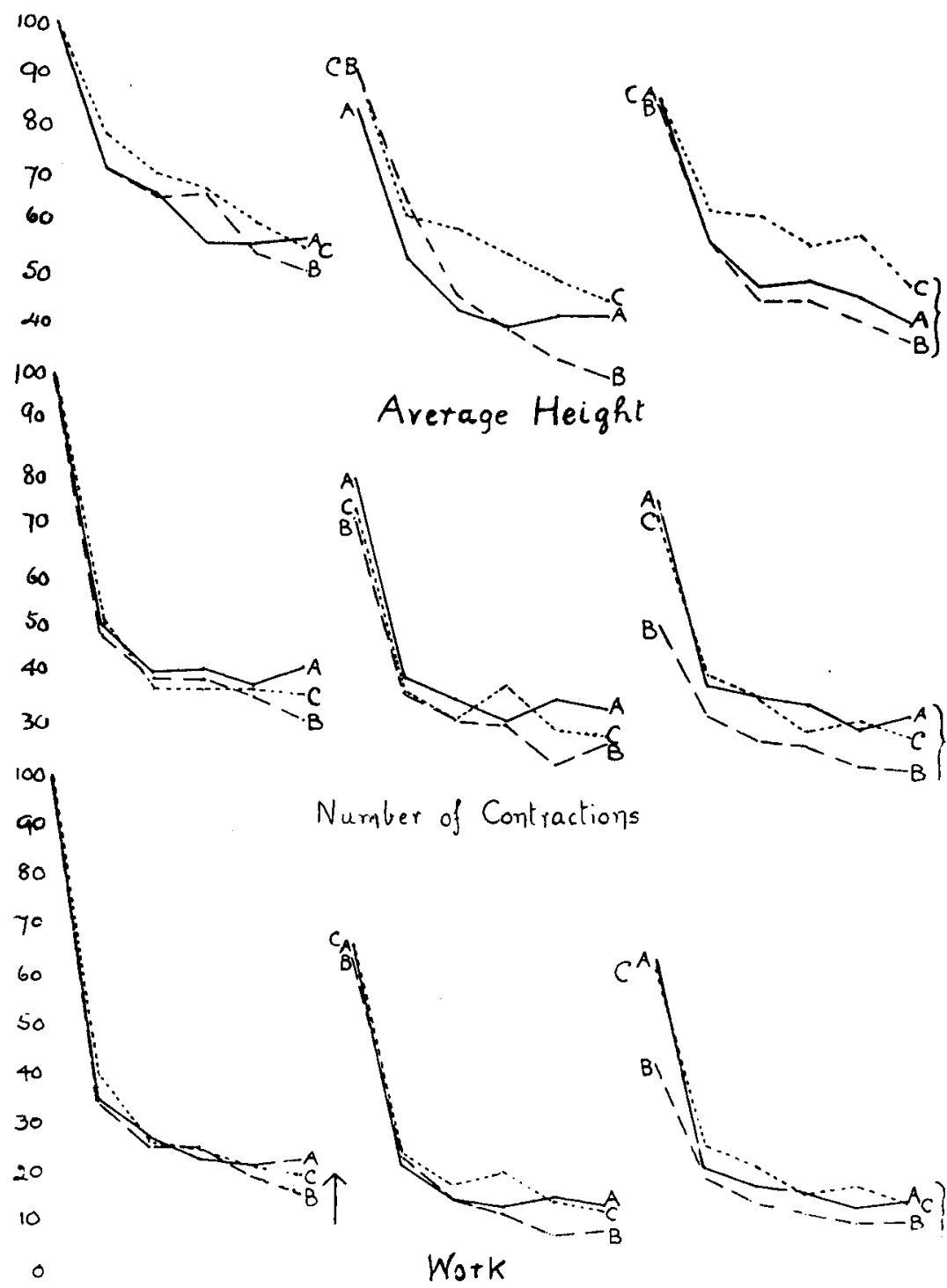

Frg. 1. Experiment $W$. i. $A$, Control mixture. B, Alcohol 5 c.c. $C$, Alcohol 10 c.c. Arrow shows when the dose was administered.

less was done on the days on which only 5 c.c. were taken than on the other two groups of days, but for this set also Fig. 1 shows 
that there is very little difference in the course of the three curves, i.e. there is no indication of any effect produced from ten to twenty-five minutes after taking the alcohol. In the case of the third set there is a very close correspondence between the curves for the control days and those on which the larger dose of alcohol was taken, but the curve for the days on which only 5 c.c. were taken falls below the others, especially for the first ergogram, and the total amount of work for this set is distinctly less than on the other two groups of days.

It is very unlikely that a dose of 5 c.c. would produce a diminution in the amount of work while double the dose has no effect, and we can have little hesitation in ascribing the nature of the $B$ curve to some accidental factor. The other curves of Fig. 1 give the course of the numbers of contractions and of the average heights of the contractions respectively, the latter being obtained by dividing the total height through which the weight was lifted by the number of contractions. It will be seen that there is no definite indication of an alcohol effect on the number of the contractions except in the third set, when it becomes clear that the course of the $B$ curve for the work was determined chiefly by this feature of the ergogram.

The curves representing the height of the contractions, on the other hand, though far less regular than those for either the amount of work or the number of contractions, show an increase on the days on which 10 c.c. of alcohol was taken, but it will be noted in Fig. 1 that the curve representing the height was showing a distinct tendency to rise on these days in the first set, i.e. before any dose had been taken, and it is doubtful whether any significance can be attached to the rise of this curve in the remaining sets ${ }^{1}$.

Experiment ii. This lasted for six days, from April 8-13. Three sets of six ergograms were recorded at half-hour intervals and the dose, whether of alcohol or control, was taken between the first and second ergograms of the first set, the doses of alcohol being 5 and 10 c.c. as in the first experiment. The work was done in the afternoons instead of in the mornings, but at the same interval after a light lunch corresponding in kind and amount to the breakfast of the first experiment. The intervals were occupied with the task of multiplication, using for this purpose the Rechenhefte of Kraepelin?

1 The inferiority of the $A$ and $B$ curves as regards the height of the contractions is almost entirely due to the two first days of the experiments when the contractions became very amall towards the end of the day.

2 The special methods and results of this work will be recorded elsewhere. 
In this and all succeeding experiments the subject took his own readings, the two minutes' interval between successive ergograms affording ample time for this and for any necessary adjustments of the ergograph. That the subject should take his own readings has some disadvantages, but it was not possible for another person to be present to record them in all cases, and unless this could be done in all cases, it was thought best that it should be done in none. The whole business of reading the scale and making any necessary adjustments so soon settles down to a steady routine that the subject is not led to think about the relations of the readings he is recording, and we are not at all sure that the method of taking one's own readings is not less disturbing than if the subject has two minutes of complete leisure between each pair of ergograms for reflexion on the nature of his performance. Further, there is the great advantage that the presence of another person in the experimental room, with all the possible sources of disturbance involved, can be dispensed with.

TABLE II. Experiment W. ii. Work. Average day. Left hand. Weight $4.5 \mathrm{~kg}$. Dose one minute after first ergogram.

\begin{tabular}{|c|c|c|c|c|c|c|c|c|c|}
\hline \multirow[b]{2}{*}{$\begin{array}{c}\text { Ergo- } \\
\text { gram } \\
1\end{array}$} & \multirow[b]{2}{*}{$\begin{array}{c}\text { Control } \\
6.8(100)\end{array}$} & \multicolumn{2}{|l|}{ First set } & \multicolumn{3}{|c|}{ Second set } & \multicolumn{3}{|c|}{ Third set } \\
\hline & & $\begin{array}{c}\text { 5 c.c. } \\
\text { Alecohol } \\
6.7(100)\end{array}$ & $\begin{array}{c}10 \text { c.c. } \\
\text { Alcohol } \\
6.9(100)\end{array}$ & $\begin{array}{c}\text { Control } \\
4 \cdot 6(69)\end{array}$ & $\begin{array}{c}5 \text { c.c. } \\
\text { Alcohol } \\
6.8(102)\end{array}$ & $\begin{array}{l}10 \text { c.c. } \\
\text { Alcohol } \\
6.8(99)\end{array}$ & $\begin{array}{c}\text { Control } \\
5 \cdot 3(79)\end{array}$ & $\begin{array}{c}5 \text { c.c. } \\
\text { Alcohol } \\
5 \cdot 9(88)\end{array}$ & $\begin{array}{l}10 \text { c.c. } \\
\text { Alcohol } \\
4 \cdot 8(70)\end{array}$ \\
\hline 2 & $2 \cdot 8(42)$ & $3 \cdot 0(45)$ & $4 \cdot 0(58)$ & $3 \cdot 1(47)$ & $3 \cdot 1(46)$ & $3 \cdot 2(46)$ & $3 \cdot 0(45)$ & $2.4(37)$ & $2 \cdot 4(36)$ \\
\hline 3 & $1 \cdot 9(28)$ & $2 \cdot 6(40)$ & $3 \cdot 2(46)$ & $2 \cdot 8(41)$ & $3 \cdot 1(47)$ & $2 \cdot 3(34)$ & $2 \cdot 4(35)$ & $2 \cdot 6(39)$ & $2 \cdot 6(38)$ \\
\hline 4 & $2 \cdot 1(31)$ & $2 \cdot 7(41)$ & $2.5(36)$ & $2 \cdot 2(32)$ & $2 \cdot 6(39)$ & $2 \cdot 3(34)$ & $2 \cdot 3(34)$ & $2 \cdot 5(38)$ & $2 \cdot 2(32)$ \\
\hline 5 & $1.7(24)$ & $2 \cdot 3(35)$ & $2 \cdot 8(40)$ & $2 \cdot 4(36)$ & $2 \cdot 3(34)$ & $2 \cdot 1(31)$ & $1.8(27)$ & $2 \cdot 4(35)$ & $1.8(26)$ \\
\hline 6 & $2 \cdot 0(30)$ & $2 \cdot 7(40)$ & $3 \cdot 1(45)$ & $2 \cdot 3(35)$ & $3 \cdot 1(46)$ & $2 \cdot 1(30)$ & $1.9(28)$ & $2 \cdot 5(38)$ & $1.9(28)$ \\
\hline Total & & $20 \cdot 0$ & 22.5 & $17 \cdot 4$ & $21 \cdot 0$ & $18 \cdot 8$ & $16 \cdot 7$ & $18 \cdot 3$ & $15 \cdot 7$ \\
\hline
\end{tabular}

The special interest of this experiment lies in the failure of the control. The larger dose of 10 c.c. was definitely recognised on each occasion and the presence of alcohol was suspected in the case of the smaller dose. The figures given in Table II. and those represented graphically in Fig. 2 show a definite increase on the alcohol days, greater on those when the larger dose was taken, and this increase was apparent immediately after the dose was taken. It continued to the end of the first set and was also distinctly present in the first ergogram of the second set, this curve falling slightly below that of the normal days in the remaining ergograms. The curves for number and height of the contractions show that the increase in the amount of work on the alcohol days was chiefly due to an effect on the former, 
though there was also a slight increase in the height in the first set on the two alcohol days, the curve for the smaller dose, however, here rising above that for the larger.
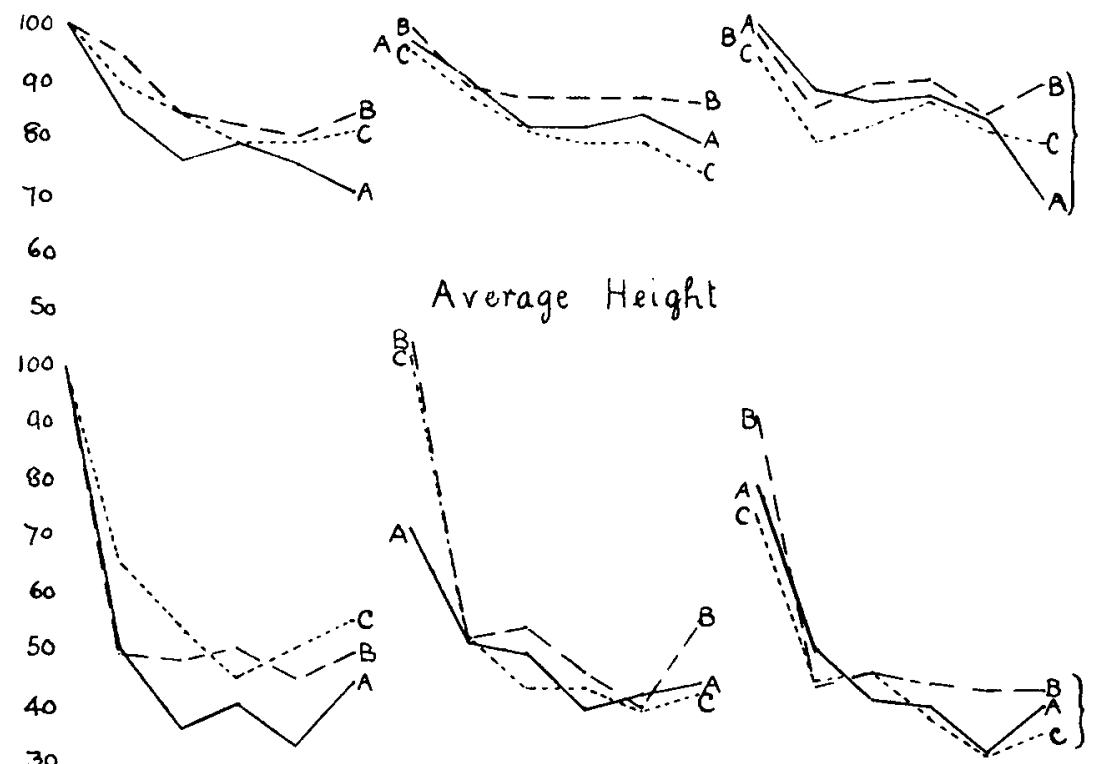

30

Number of Contractions

20

C!
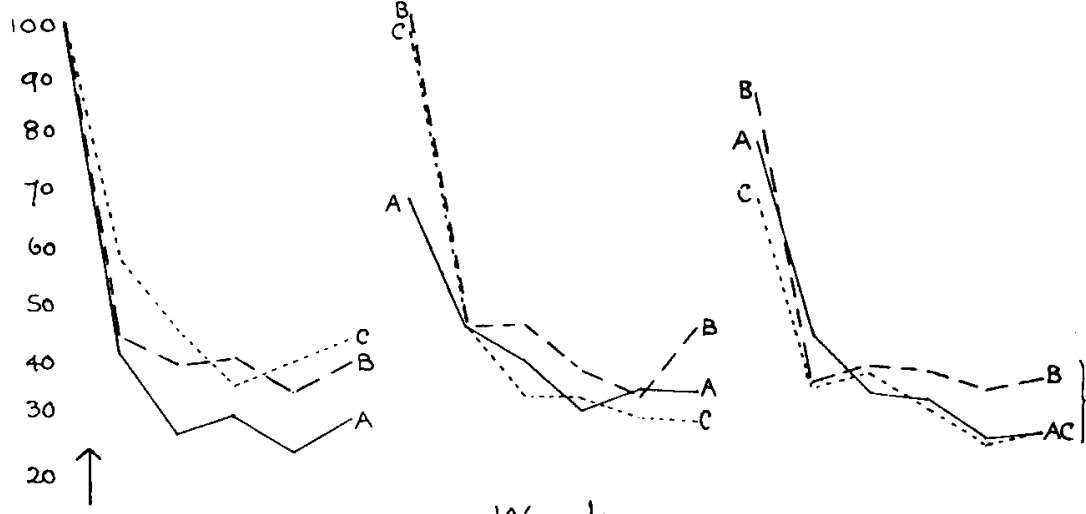

10

Work

0

Fra. 2. Experiment $W$. ii. $A$, Control mixture. $B$, Alcohol 5 c.c. $C$, Alcohol 10 c.c.

The action of alcohol in this experiment was of the same kind as that which has been described by most previous workers, viz., an 
immediate increase followed by a reaction shown in a fall below the normal, and it is interesting that this kind of action should have shown itself in an experiment in which there was a failure of the control, so that the feature of interest would be awakened.

Experiment iii. The control having failed in the second experiment, it became necessary to modify the mixtures used for this purpose. The mixtures had so far contained capsicum, cardamoms and chloroform only, to which Dr Dixon now added some peppermint. The new control was completely successful, the disguise being so perfect that in this and succeeding experiments the subject was wholly unaware, so far as taste was concerned, whether he had taken alcohol or the control mixture.

The experiment was begun on May 7 with the idea of testing the influence of doses of 10 and 20 c.c. of absolute alcohol by exactly the same methods as in the second experiment, except that the intervals on half the days were to be occupied with multiplication while on the other half the place of the multiplication was to be taken by type-writing. At the end of five days the experiment was unavoidably interrupted by which time only one day's work had been done with each dose. The smaller dose of 10 c.c. had given a completely negative result while with the larger dose of 20 c.c. there had been an increase only noticeable in the first ergograms of the second and third sets. As there did not seem evidence of any definite effect we decided not to repeat this experiment but to proceed directly to larger doses, especially as the dose of 20 c.c. was to be tried in the next experiment.

Experiment iv. This lasted for twenty days, on six of which no dose of any kind was taken, on five a control mixture was taken, while on the other days the doses of alcohol were either 20 or 40 c.c. of absolute alcohol. Each dose was taken between the first and second ergograms of the first set.

On each day four sets were recorded, each of six ergograms. The interval between the first and second and between the second and third sets was half an hour, but between the third and fourth sets it was increased to one hour. The first and second intervals were occupied in either multiplication or type-writing, the amount done in each five minutes being recorded with the help of a five minutes' clock. This work was done for twenty-five minutes, leaving time at the beginning and end for the necessary adjustments of the ergograph. The third interval of an hour was passed in gentle walking in the open air and in light reading, while a little food was also taken. 
Another modification introduced into this experiment was that the work with the ergograph was done in two ways. On some days the finger was allowed to contract to the full extent in the ordinary way; on the other days an obstacle was placed in the course of the contracting finger so that the contractions were only allowed to reach
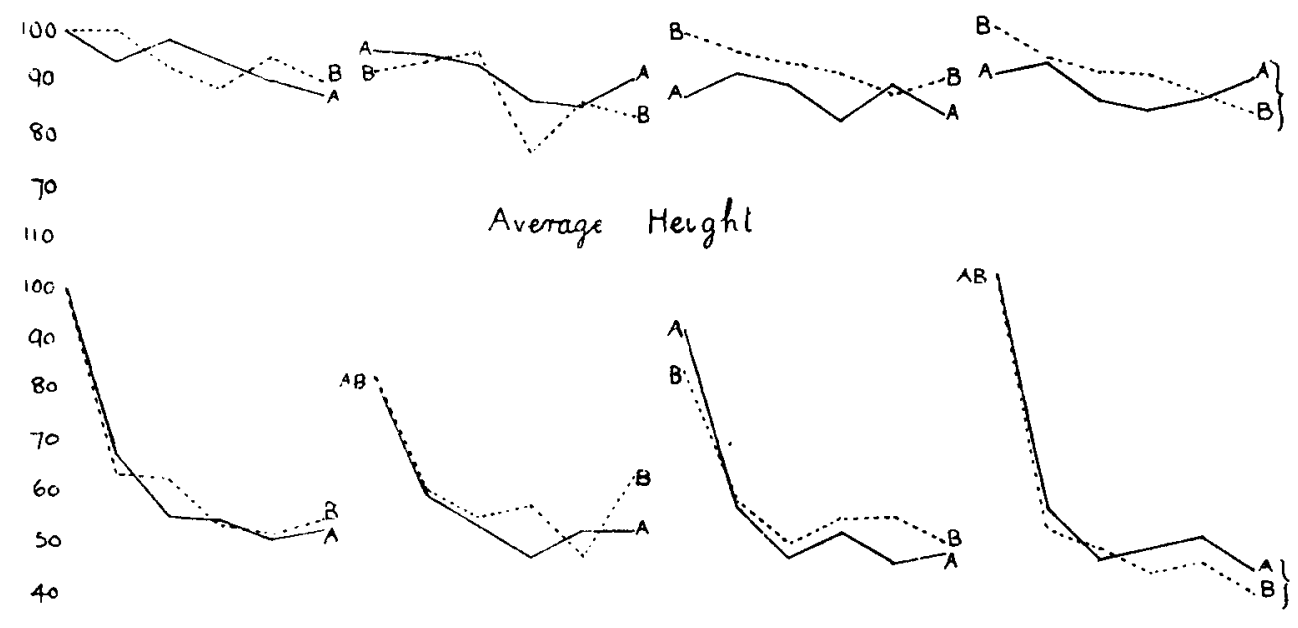

30

Number of Coniractions

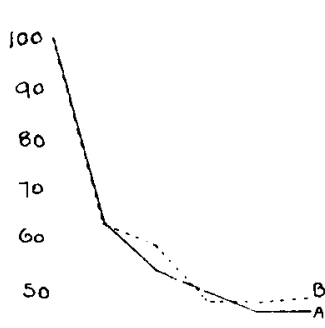

40
30
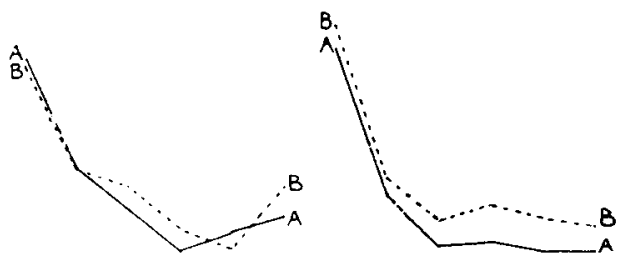

Work

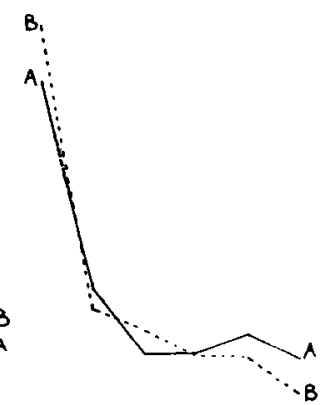

Fig. 3. Experiment $W$. iv. Complete contractions. $A$, Control mixture. $B$, Alcoliol 20 c.c.

two-thirds of their normal extent. We shall speak of these methods as those of complete and incomplete contractions respectively'.

1 The consideration of the motive for this procedure and the different results of the two procedures must be deferred for another occasion. 
As in this paper we are dealing only with small doses of alcohol, we give in the following tables and curves the results for the smaller dose of 20 c.c. and leave the results with the larger dose of 40 c.c. for a later communication. The figures for the smaller dose with the two kinds of contraction are given separately.

TABLE III. Experiment W. iv. Work. Complete contractions. Left hand. Weight $4.5 \mathrm{~kg}$. Dose taken one minute after first ergogram.

\begin{tabular}{|c|c|c|c|c|c|c|c|c|}
\hline & irst set & \multicolumn{2}{|c|}{ Second set } & \multicolumn{2}{|c|}{ I'hird set } & \multicolumn{2}{|c|}{ Fourth set } \\
\hline & & $\begin{array}{r}20 \\
\text { Alcohol }\end{array}$ & Control & $\begin{array}{c}20 \text { c.c. } \\
\text { Alcohol }\end{array}$ & Control & $\begin{array}{l}20 \text { c.c. } \\
\text { dleohol }\end{array}$ & & $\begin{array}{r}20 \text { c.c. } \\
\text { Alcohol }\end{array}$ \\
\hline 1 & $6.6(100)$ & $5.4(100)$ & $5 \cdot 1(78)$ & $4 \cdot 2(77)$ & $5 \cdot 2(80)$ & $4 \cdot 6(84)$ & $6 \cdot 1(93)$ & $5 \cdot 7(104)$ \\
\hline 2 & $4.2(64)$ & $3.4(63)$ & $3 \cdot 7(57)$ & $3.0(56)$ & $3 \cdot 4(51)$ & $2 \cdot 9(54)$ & $3 \cdot 1(52)$ & $2 \cdot 6(48)$ \\
\hline $\mathbf{3}$ & $3 \cdot 6(54)$ & $3 \cdot 2(59)$ & $3 \cdot 2(48)$ & $2 \cdot 9(53)$ & $2 \cdot 7(41)$ & $2 \cdot 5(46)$ & $2 \cdot 6(39)$ & $2 \cdot 4(44)$ \\
\hline 4 & 3.3 (50) & $2 \cdot 6(48)$ & $2 \cdot 6(40)$ & $2 \cdot 4(44)$ & $2 \cdot 7(42)$ & $2 \cdot 6(49)$ & $2 \cdot 6(39)$ & $2 \cdot 1(39)$ \\
\hline 5 & $3 \cdot 0(46)$ & $2 \cdot 6(48)$ & $2.9(44)$ & $2 \cdot 2(40)$ & $2 \cdot 6(40)$ & $2.5(46)$ & $2 \cdot 8(43)$ & $2 \cdot 1(39)$ \\
\hline 6 & $3 \cdot 0(46)$ & $2 \cdot 6(49)$ & $3 \cdot 1(47)$ & $2 \cdot 8(52)$ & $2.6(40)$ & $2 \cdot 4(45)$ & $2.5(38)$ & $1.7(31)$ \\
\hline Total & $23 \cdot 7$ & $19 \cdot 8$ & 20.6 & $17 \cdot 5$ & $19 \cdot 2$ & 17.5 & $20 \cdot 0$ & 16.6 \\
\hline
\end{tabular}

The figures for the amount of work with the complete contractions given in Table III. and represented graphically in Fig. 3 show not the slightest trace of an immediate effect, and the two curves for the first set run together as well as if no drug had been given. In the second set there is also no definite indication of an effect, which only appears in the third set begun an hour and a half after the alcohol had been taken. The fact that the alcohol curve in this set is consistently above that for the normal days suggests that we may possibly have to do here with a real drug effect, though of only slight amount, which has wholly disappeared an hour later. The other curves show that this increase is due to an effect on both number and height of the contractions, perhaps chiefly on the former.

The results with the incomplete contractions shown in Table IV. and Fig. 4 seem to show an immediate depressing effect of the alcohol, but not of any great amount. In the second set this is replaced by an increase on the alcohol days, which becomes still more definite in the third set to disappear in the last. This correspondence with the complete contractions in showing a definite increase in the third set is almost certainly significant, and seems to point to a stimulating action of the alcohol asserting itself most definitely about an hour and a half after its administration.

This occurrence of a late increase with the incomplete contractions makes it probable that the fall of the curve in the first set is due to 


\section{W. H. R. Rivers and H. N. Webber}

some accidental circumstance; certainly there was no increase of the kind which has usually been recorded.

TABLE IV. Experiment W. iv. Work. Incomplete contractions. Left hand. Weight $4.5 \mathrm{~kg}$. Dose taken one minute after first ergogram.

\begin{tabular}{|c|c|c|c|c|c|c|c|c|}
\hline \multirow[b]{2}{*}{ Ergogram } & \multicolumn{2}{|c|}{ Firat net } & \multicolumn{2}{|c|}{ Second set } & \multicolumn{2}{|c|}{ Third set } & \multicolumn{2}{|c|}{ Fourth set } \\
\hline & Control & $\begin{array}{l}20 \text { c.c. } \\
\text { Alcohol }\end{array}$ & Control & $\begin{array}{l}20 \text { c.c. } \\
\text { Alcohol }\end{array}$ & introl & $\begin{array}{l}20 \text { ce.c. } \\
\text { Alcohol }\end{array}$ & & $\begin{array}{l}20 \text { Cc. } \\
\text { Alcohol }\end{array}$ \\
\hline 1 & $7 \cdot 1(100)$ & $5 \cdot 9(100)$ & $4 \cdot 6(61)$ & $3 \cdot 8(62)$ & $3 \cdot 9(53)$ & $4 \cdot 3(73)$ & $5 \cdot 2(69)$ & $4 \cdot 4(72)$ \\
\hline 2 & $4 \cdot 0(58)$ & $2 \cdot 8(48)$ & $2.8(38)$ & $2 \cdot 7(45)$ & $2 \cdot 9(41)$ & $2 \cdot 6(43)$ & $4 \cdot 4(54)$ & $2 \cdot 7(45)$ \\
\hline 3 & $3 \cdot 6(50)$ & $2 \cdot 3(40)$ & $2 \cdot 7(36)$ & $2 \cdot 4(40)$ & $2 \cdot 0(28)$ & $2 \cdot 2(37)$ & $1 \cdot 8(26)$ & $2 \cdot 1$ (35) \\
\hline 4 & $3 \cdot 3(44)$ & $2 \cdot 3(38)$ & $2 \cdot 8(38)$ & $2.0(35)$ & $1.8(25)$ & $2 \cdot 3(37)$ & $2 \cdot 0(27)$ & $2 \cdot 0(33)$ \\
\hline 5 & $2 \cdot 8(37)$ & $2 \cdot 2(37)$ & $1.8(25)$ & $2 \cdot 0(33)$ & $1.9(26)$ & $2 \cdot 2(37)$ & $2 \cdot 2(29)$ & $2 \cdot 1(35)$ \\
\hline 6 & $2 \cdot 9(39)$ & $2 \cdot 1(35)$ & $2 \cdot 3(31)$ & $2 \cdot 7(45)$ & $2 \cdot 9(39)$ & $1.9(31)$ & $2 \cdot 1(28)$ & $1.8(30)$ \\
\hline & & & & & & & & 1. \\
\hline
\end{tabular}

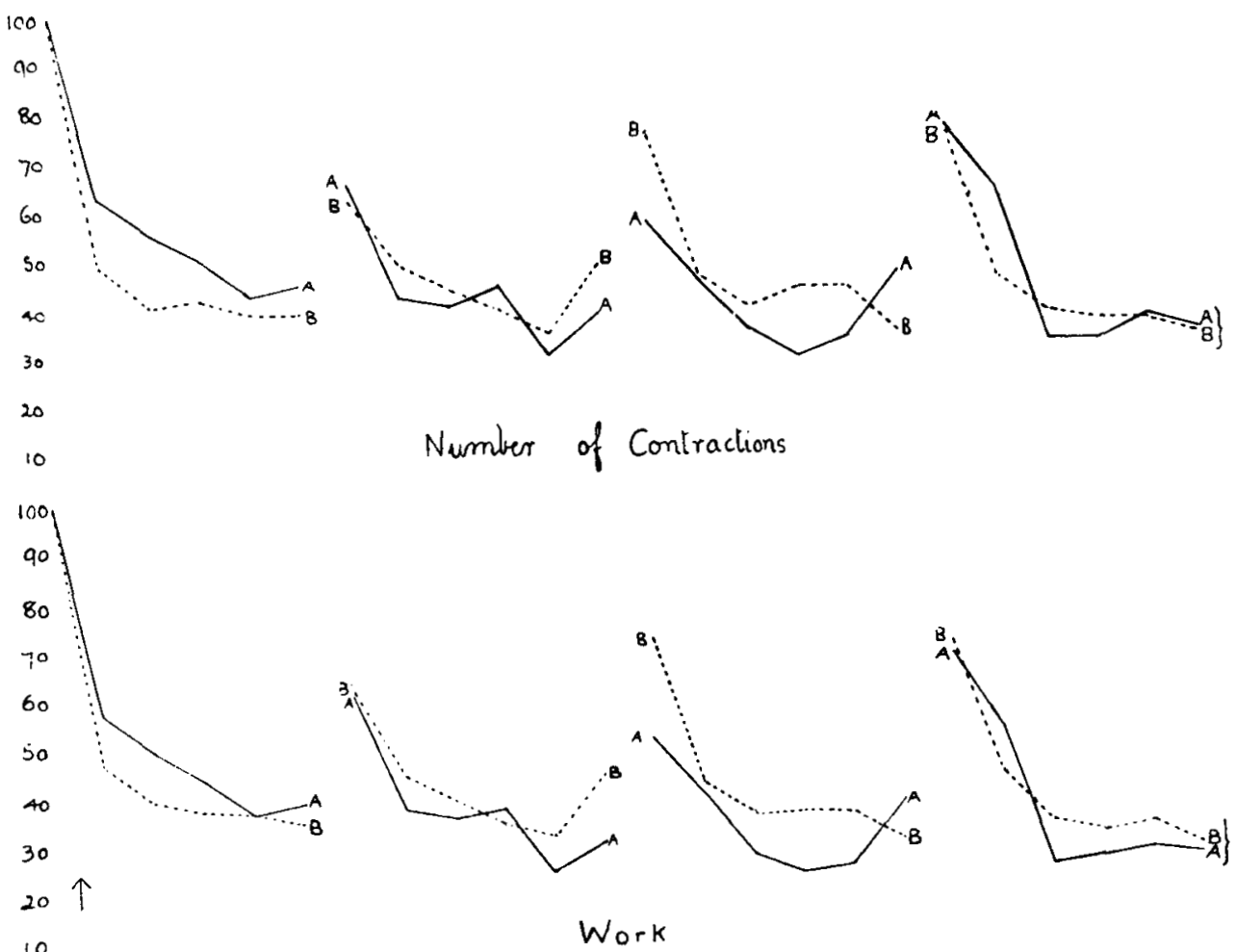

0

Fia. 4. Experiment $W$. iv. Incomplete contrections. $A$, Control mixture. $B$, Alcohol 20 c.c.

This fourth experiment thus confirms the first and third in showing no trace of the immediate stimulating action when there is an adequate 
control and any increase which is found is considerably delayed, being most pronounced about an hour and a half after the alcohol has been taken.

The only definite increase thus occurs at a time when the effect described by most previous workers has disappeared or at a period beyond that to which they have followed the effects of the drug. The reality and nature of this late effect must be left for future work and we wish to dwell especially on the absence of the immediate stimulating effect.

A word must be said here on the validity of the procedure of expressing the results in their relation to the first ergogram. In the first experiment, and in the experiments with caffeine which we have recorded elsewhere ${ }^{1}$, the dose of drug or control was not taken till after the first set had been completed so that we are able to express the course of the work in terms of the whole of the first set as well as in terms of the first ergogram, and the correspondence of the two ways of expressing the results in those cases can leave little doubt about the genuineness of the results.

In the later alcohol experiments of $W$. the dose was taken immediately after the first ergogram so that in this case we have only one ergogram to act as a standard. As a general rule, however, the course of the ergograms of the first set on the normal days is so constant and the later ergograms stand in so definite a relation to the first that we have little doubt of the validity of our procedure. Still in such a case there must always be the possibility that the first ergogram may be exceptional in some way, and in later experiments with other subjects we have not given the drug or control till a whole set had been recorded to act as a standard.

\section{The experiments of the subject $R$.}

The experiments of this subject were much less satisfactory than those of W. owing to the muscular pain produced when sets of six or even of three or four ergograms were recorded. His first experiment in March, 1906, was planned to correspond with the first experiment of W., doses of 5 and 10 c.c. of alcohol being taken ten minutes before the beginning of the second set. This experiment could only be continued for five days, the results of which, though irregular, gave no indication of an alcohol effect.

1 Journ. Physiol. 1907, Vol. xxxvi. p. 33. 
Experiment ii. It was not possible to do any further satisfactory work till August of the same year, when after prolonged training an experiment with incomplete contractions lasting for six days was carried out with doses of 10 and 20 c.c., taken one minute before beginning the second set. Five sets were recorded, each of four instead of six ergograms as usual. As in our other experiments the two first intervals were balf an hour and those between the later sets an hour, and were passed in some light occupation, or in the open air, the corresponding intervals on different days being always occupied in the same manner.

The results are given in Table V. The figures for the individual ergograms are extremely irregular, for the amount of practice at this stage was still insufficient and the contractions often produced pain. The figures of the bottom line of the table, which give the total work of each set, show little difference in the work of the first sets on the three groups of days, before any dose had been taken, and there is no difference in the figures for the second set begun one minute after administration of the dose, i.e. there is no trace of any immediate effect. The figures for the third set, on the other hand, seem to show an alcohol effect, the increase being greater with the larger than with the smaller dose. The fourth set shows no trace of an alcohol effect, while the individual ergograms of the last set are so extremely irregular that little importance can be attached to the differences in the totals, especially as there is little difference between the amounts for the control days and those on which the larger dose was taken. The only indication of an effect is, therefore, in the third set, begun threequarters of an hour after the alcohol was taken, and the result of the succeeding experiment makes it doubtful whether the difference was due to anything more than the irregularity caused by the imperfect condition of training.

Experiment iii. From Aug. 27 to Sept. 1, 1906, a six days' experiment was carried out in which five sets, each of six ergograms, were recorded with the right hand and with complete contractions. The doses of alcohol were 20 and 40 c.c. and they or the control were taken one minute before beginning the second set of ergograms. Even with the larger number of ergograms in each set, and though the contractions were complete, there was less pain than in the second experiment, and the form of the curves showing the course of the individual ergograms (see Fig. 5) is far more regular than in that experiment, though still far from attaining the regularity of the fully trained condition. As in the case of $\mathrm{W}$. the results with the larger dose will be left for another 


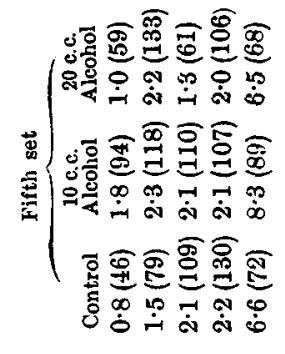

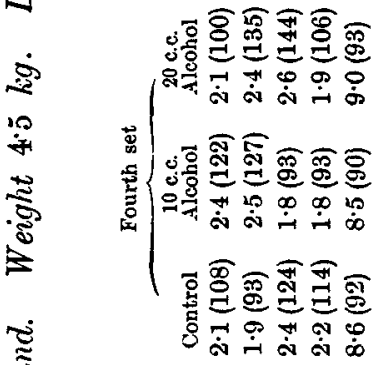

赵

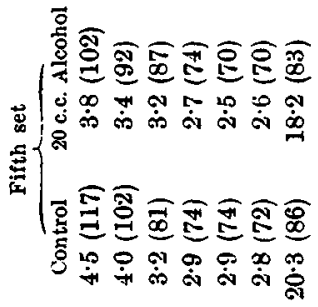

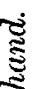

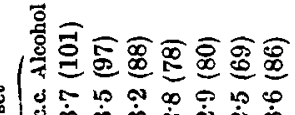

:

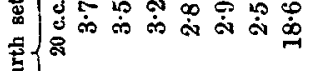

空

ญे

芯

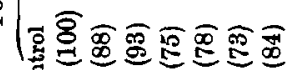

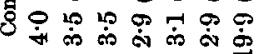

於

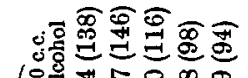

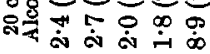

๘

芯芯芯焉

8

हัँ

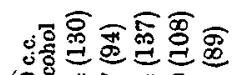

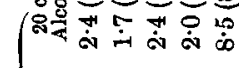

岕

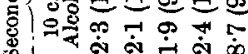

ثُ

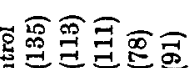

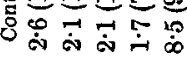

$:=\dot{7}$

시

(

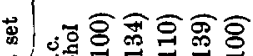

स

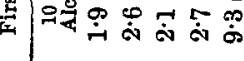

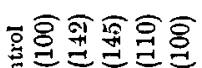

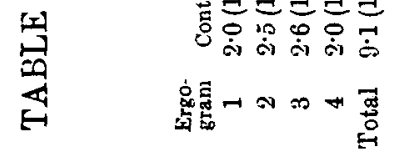

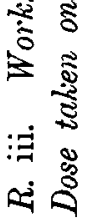

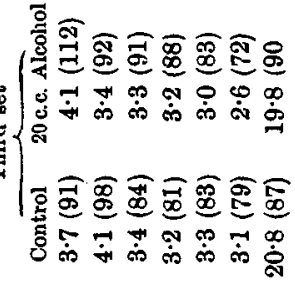

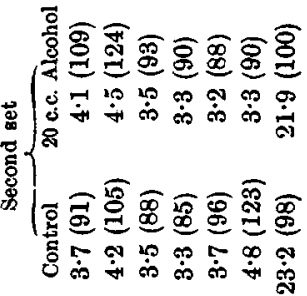

(ָ)

$\stackrel{8}{p}$

量

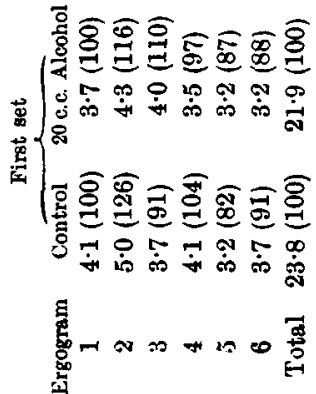


communication and the full results for the control days and those on which 20 c.c. were taken are given in Table VI.

The total amounts for the whole sets given in the bottom line of this table show no trace of an alcohol effect. The results for the individual ergograms, expressed graphically in Fig. 5, show what may be an alcohol effect in the second set begun almost directly after taking
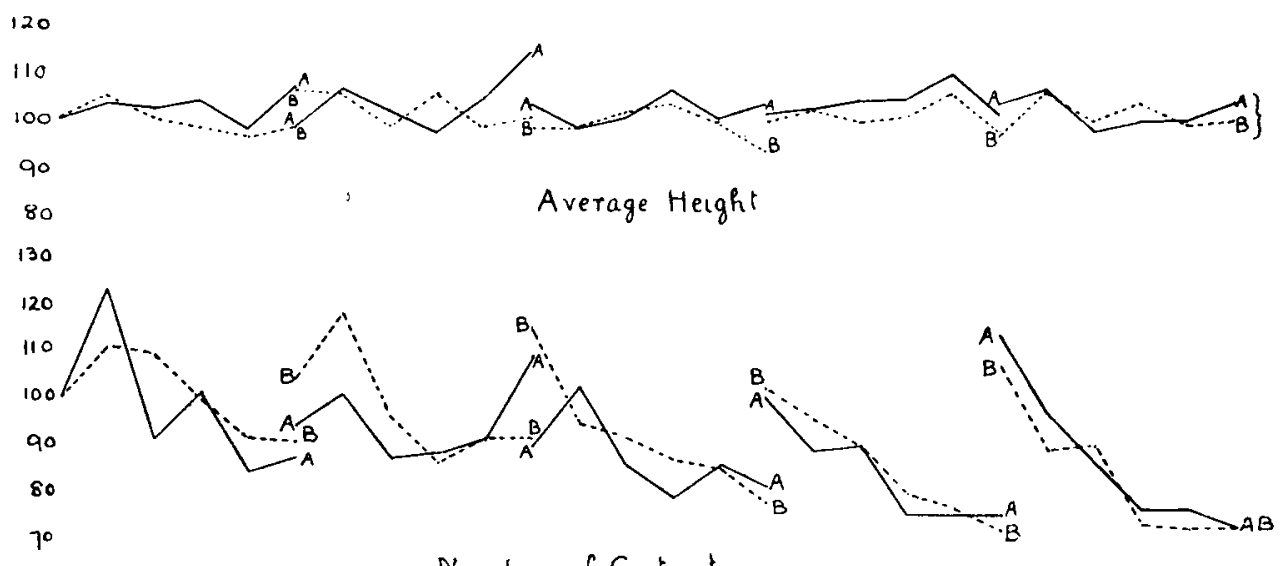

bo Number of Contractions

130

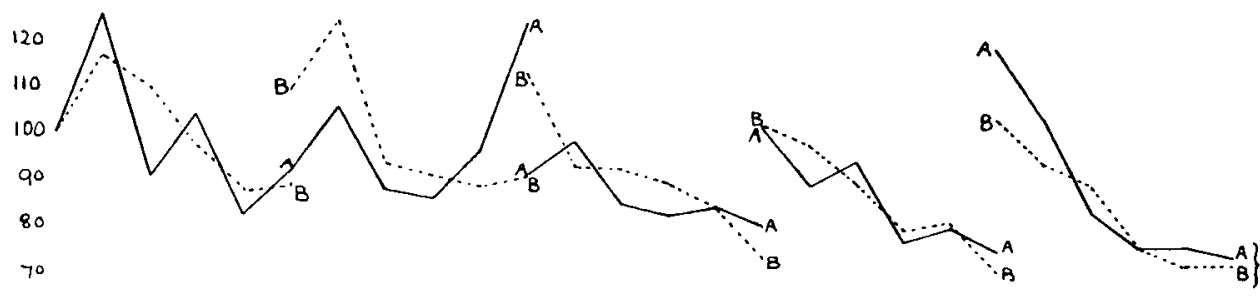

Work

Fra. 5. Experiment R. iii. A, Control mixture. $B$, Alcohol 20 c.c.

the dose, but the very abnormal form of the curve for the control days ${ }^{1}$ shows that much weight cannot be laid on the record of this set. The first part of the control curve of the third set is also abnormal, probably owing to the existence of some pain, and it is only the first ergogram of

1 The great rise at the end of this set was chiefly due to a disturbance which occurred on one of the control days. The drum did not act properly and the mental excitement thus produced was followed, as usual, by a large incresise in the amount of work. 
this set in which there is any decided difference between the alcohol and control days, while in the fourth set the two curves run very closely together.

This experiment, then, differs from the preceding in giving some indication of an immediate effect, but, on the other hand, there is no trace of the increase after an hour and a half which occurred in the case of $W$. and the nature of the early increase gives one no confidence in its dependence on the action of the alcohol.

As in this experiment the dose was not taken till the first set of ergograms was concluded, it is possible to use the average ergogram of this set as a standard by means of which to express the course of the individual ergograms. We have therefore constructed curves resembling those of Fig. 5 except that each ergogram is expressed, not as a percentage of the first ergogram, but as a percentage of the average of the whole of the first set, i.e. an average obtained by dividing the total work of this set by six. The curves so constructed, however, were found to agree very closely in their general features with those already given.

\section{Conclusions.}

The chief result of our experiments is that we have failed to confirm the conclusion of nearly all previous workers that small doses of alcohol, from 5 to 20 c.c., have an immediate stimulating or depressing action on the capacity for muscular work as tested by the ergograph. Our experiments have differed from all previously recorded in the use of control substances by means of which we have been successful in rendering the days on which alcohol was taken indistinguishable from the normal days, and in the only case in which we have found a definite immediate effect there had been failure of our control. The natural conclusion is that the results of previous workers have been due, not to the physiological effects of the alcohol, but to the presence of certain factors, and especially interest and sensory stimulation, the influence of which we have been able to exclude.

Before, however, accepting this conclusion it is necessary to inquire whether there have been any other differences between our experiments and those of previous workers which might explain the divergent results.

One such difference is a consequence of our use of a control. The mixtures in which we took the alcohol for purposes of disguise were decidedly unpleasant and the possibility arises that this may have 
neutralised an effect which the alcohol might otherwise have produced. The control mixture containing no alcohol, however, was equally unpleasant, and as the uupleasantness was the same on both alcohol and control days, any alcohol effect which existed ought to have become evident. Further, in later experiments to be recorded on another occasion a different control has been used decidedly pleasant to the taste, and in these experiments also there has been no evidence of an alcohol effect.

Another possibility must be borne in mind. One of the most definite results of previous work on the action of alcohol has been to show the presence of great individual differences in the susceptibility to the action of the substance, and though it is possible that these variations have been largely due to differences in the part played by the psychical factors, which it has been our business to exclude, there can be little doubt of the existence of individual differences in the true physiological action of the drug. It is possible that the two subjects whose work has been recorded in this paper are examples of insusceptibility to the action of alcohol. One of us knows, however, that he is unusually susceptible to the general effects of alcohol, and observations on the general condition of the other marle during these and other experiments ${ }^{1}$ show that he is certainly not an example of any special insusceptibility to the action of the substance.

A further piece of evidence that our negative results have been due to the use of an adequate control is derived from a short experiment on the subject W. with doses of whiskey containing 10 and 20 c.c. of absolute alcohol. These observations were made by giving the whiskey without any attempt at disguise, and it was found that both doses produced a very decided increase in the amount of work as compared with a normal day. The most noteworthy fact is that this increase was immediate exactly as in nost previously recorded work. It is of course open to anyone to say that the increase in this case was due to some component of the whiskey other than ethylic alcohol, but the immediacy of its action can leave little doubt that we had to do mainly with the action of interest and sensory stimulation. If so, we have the clearest evidence that the cause of the negative results with pure alcohol in the case of the subject $W$. was not individual insusceptibility, but the means which were taken to exclude the psychical factors which have been allowed to influence all previous results. 
There can, we think, be little doubt that the absence or slightness of the effects with small doses of alcohol which we have found are due to our use of control substances, and that the results of most of those who have found the capacity for muscular work increased under the influence of such doses as 5 and 10 c.c. have been due, not to the physiological action of the substance, but to the interest aroused by taking the alcohol and the sensory stimulation involved in swallowing it, while those who have found a diminution in the amount of work must be open to the charge of having been influenced by suggestion.

Our experiments show definitely that the factors of interest, sensory stimulation and suggestion may play a great part in the process of testing the action of a drug with the ergograph, and we hope to have shown that no future work on the action of drugs can be regarded as decisive if these factors have not been excluded by the use of an adequate control. 